\title{
0k-432 (Picibanil) In the Treatment of Ranulas
}

\author{
Muhammet Recai Mazlumoglu*
}

Otorhinolaryngology clinic, hinis sehit yavuz yurekseven state hospital, erzurum, turkey

Received: October 16, 2017; Accepted: October 24, 2017; Published: October 31, 2017

*Corresponding author: Muhammet Recai Mazlumoglu, MD Otorhinolaryngology Clinic, Hinis Sehit Yavuz Yurekseven State Hospital, 25100, Erzurum, Turkey, Tel: +90 542435 5835; Fax: +90 0442327 3632; E-mail: dr.mazlumoglu@gmail.com

\begin{abstract}
OK-432 is used as a chemotherapeutic agent in the treatment of cancer. Since 1987, however, it has been successfully used as a sclerotherapy agent in the treatment of cystic pathologies. A cystic malformation, known as ranula, is very common in the head and neck region. For this reason, sclerotherapy with OK-432 started to be used in the treatment of ranulas in the 1990s. A literature review of the use of $\mathrm{OK}-432$ in simple, plunging, and parapharyngeal extended ranulas was undertaken with a focus on case reports and published research articles. The successful use of $\mathrm{OK}-432$ in treatments and a discussion of outcomes and complications are discussed in addition to the advantages and disadvantages of $\mathrm{OK}-432$ in ranula treatment.
\end{abstract}

Keywords: OK-432; Ranula; Sclerotherapy

\section{Introduction}

\section{Ranula}

Ranula, derived from the Latin word 'rana' meaning, describes the blue, translucent swelling at the base of the mouth resembling the abdomen of a frog. Ranulas are pseudocysts formed by salivary extravasation from the sublingual and minor salivary glands [1]. The cystic wall contains no epithelial tissue, but rather granulation, connective- or fibrous-type tissue.

Ranulas can be divided into simple (intraoral) or plunging (cervical) types. Simple ranulas are limited to the base of the mouth and gradually show painless growth. On the contrary, plunging ranulas are localized under the mylohyoid muscle, grow towards the parapharyngeal area of the neck, and form a cystic swelling [2]. The ranulas seen most often in the second decade of life are of the simple type in women, while plunging ranulas are more common in males. Oral ranulas tend to be more common on the left side while plunging ranulas are more common on the right side [3].

The diagnosis of a ranula can be made primarily on clinical exam, as well as by ultrasonography (USG), computed tomography (CT), magnetic resonance imaging (MRI) and fine needle aspiration cytology (FNAC), which is primarily used for the diagnosis of the plunging ranula type [1]. CT and MRI are the most-used diagnostic modalities. On CT examination, the appearance of the 'tail sign' is vital for distinguishing plunging ranulas. However, these images are insufficient to differentiate between cystic hygroma, second branchial cleft cyst, or dermoid cysts [4]. USG can be used preoperatively to determine the characteristics of pediatric ranulas, and are a radiation-free and a rather inexpensive modality [2]. Plunging ranula diagnosis is complicated due to the absence of clinical features apart from a swelling in the neck. In this case, FNAC is useful for diagnosis. Amylase and Mucin are positive in the yellow aspirate in the ranula, whereas lymphatic malformations often contain cholesterol crystals and lymphoid and endothelial cells in watery aspirates [5].

Ranula treatment consists of observation, sclerotherapy, marsupialization, and excision with or without laser removal of sublingual glands.

\section{OK-432 (Picibanil)}

OK-432 is a lyophilized state human-driven Group A streptococcus pyogenes strain which is produced by processing with heat and benzylpenicilline. First, Ogita et al. have shown the efficiency of this agent on cystic hygroma which are being used on immunotherapy for cancer patients $[7,8]$.

Effect mechanism of OK-432 has been explained with inflammatory response produced. Inflammatory cells coming into cyst postinjection and stimulate the immune response. Endothelium permeability increases, with the release of various cytokines such as interleukin-6, tumor necrosis factor, interferon gama. And this caused the contraction of cyst by increasing the drainage of lesion to lymph ducts. Other than this, increasing the number of OK-432 natural killer and T-lymphocyte increases the contraction of cyst [9].

\section{Discussion}

The use of $0 \mathrm{~K}-432$ in ranula treatment was first reported by Ikarashi et al. in the treatment of a plunging ranula in an adult patient. For the treatment of the first plunging ranula extending to the parapharyngeal area, the first use of OK-432 was reported 
by Kinoshita et al. [10,11]. Fukase et al. in 2003 published a case series consisting of 23 oral and 11 plunging ranulas [12].

Studies in the literature are primarily focused on plunging ranula, with fewer studies describing oral ranulas or ranulas that extend into the parapharyngeal space [13-22]. In addition, few studies have made a distinction between children and adults, with only a handful of studies performed in children $[18,19]$. Among all studies, Ohta et al. had the highest number of ranulas in their study with 48 patients observed [17].

In patients who will undergo OK-432 treatment, a history of penicillin allergy should be elucidated as the OK-432 formulation contains benzyl penicillin. It may even be appropriate to perform a skin allergy test [20]. The application is performed as described by Ogita et al. with $0.1 \mathrm{mg}$ of OK-432 (defined as 1 Klinische Einheit (KE) unit) mixed with $10 \mathrm{ml}$ of saline after the lesional volume is calculated [8]. Under USG guidance, the ranula content, often described as a yellowish mucoid fluid, is aspired as much as possible. Then the OK-432 mixture is added to the cyst in the same volume as the aspirated liquid. This procedure is often performed without the need for local anesthetic [16]. Syringes used are between 18-27 gauge and depend on the location of the cystic lesion as well as the clinical situation of the patient $[11,17]$. It is not always clear how much OK-432 mixture should be given; however, the general practice is between 0.1-0.5 KE [16]. This amount varies according to the experience and preference of the physician.

Previously, patients were hospitalized for the application of OK-432 in the treatment of ranulas, but this practice was deemed unnecessary. Only those at risk of airway obstruction should be hospitalized [21]. Post-sclerotherapy follow-up also varies according to the clinician's preference. However, follow-up on days $2,7,14$, and 28 are generally considered suitable. USG and CT are often used for monitoring. Sclerotherapy can be performed again 4-6 weeks after the initial application [12]. Although the number of applications can vary, most patients require between 1-5, with greater than 5 applications rarely needed [17].

The outcomes following ranula treatment with OK-432 vary considerably among studies. Rho et al. [13] reported a complete reduction rate of $33 \%$, whereas Fukase et al. reported this rate to be above $90 \%$ [12]. In children, this rate is $70 \%$ in simple ranulas but over $90 \%$ in the plunging ranula type $[18,19]$. Surprisingly, in ranulas with parapharyngeal extension, the treatment success rate is outstanding. Ohta et al. reported adequate treatment in all five of their patients [22].

OK-432 is an uncomplicated treatment with few complications. The most common complaints in ranula treatment are local pain, swelling, redness, and mild fever; these symptoms often resolve within a few days. Fukase et al. reported the rate of occurrence of these complications as $53 \%$ and stated that fever was correlated with OK-432 dose [12]. Apart from these, odynophagia, injection outside the cyst, and penicillin allergy are other important complications. Abscess and scar development have not been reported; therefore, there is no need for preventative antibiotic therapy. It is also known that the surgery after sclerotherapy is not more complex [16].

The use of OK-432 in the treatment of ranula has many advantages, including 1) ease of application, 2) cosmetic appearance, 3) cost of treatment, 4) alternative surgical options if treatment failure occurs, 5) few complications, 6) no requirement for hospitalization, and 7) no need for general anesthesia.

The disadvantages of sclerotherapy include 1) difficulty in obtaining the sclerotherapeutic agent in some countries, 2) the need for frequent applications, 3) the need for periodic monitoring, and 4) that it cannot be applied to patients with a penicillin allergy.

Considering these advantages and disadvantages, using $\mathrm{OK}$ 432 as the first line in the treatment of simple, plunging, and parapharyngeal ranulas in all age groups is a logical choice. Further studies into the dosing of $0 \mathrm{~K}-432$ are required.

\section{References}

1. Zhi K, Gao L, Ren W. What is new in management of pediatric ranula?. Curr Opin Otolaryngol Head Neck Surg. 2014; 22(6): 525-529; Doi: 10.1097/MO0.0000000000000103

2. Kim J. Ultrasound-guided sclerotherapy for benign non-thyroid cystic mass in the neck. Ultrasonography. 2014; 33(2): 83-90; Doi: 10.14366/usg.13026

3. Zhao YF, Jia Y, Chen XM, Zhang WF. Clinical review of 580 ranulas. Oral Surg Oral Med Oral Pathol Oral Radiol Endod. 2004; 98(3): 281-287; Doi: 10.1016/j.tripleo.2004.01.013

4. Miller MB, Rao VM, Tom BM. Cystic masses of the head and neck: pitfalls in CT and MR interpretation. AJR Am J Roentgenol. 1992; 159: 601-607

5. Alka P, Kumar R. Cystic hygroma: cytological and radiological corelation. J Clin Diagn Res. 2011; 5: 1008-1010

6. Pandit RT, Park AH. Management of pediatric ranula. Otolaryngol Head Neck Surg. 2002; 127(1): 115-118; Doi: 10.1067/mhn.2002.126590

7. Sung MW, Lee DW, Kim DY, Lee SJ, Hwang CH, Park SW, et al. Sclerotherapy with picibanil (OK-432) for congenital lymphatic malformation in the head and neck. Laryngoscope. 2001; 111((8):1430-1433; Doi: 10.1097/00005537-200108000-00020

8. Ogita S, Tsuto T, Tokiwa K, Takahashi T. Intracystic injection of OK-432: a new sclerosing therapy for cystic hygroma in children. Br J Surg. 1987; 74(8): 690-691

9. Kim MG, Kim SG, Lee JH, Eun YG, Yeo SG. The therapeutic effect of OK432 (picibanil) sclerotherapy for benign neck cysts. Laryngoscope. 2008; 118(12): 2177-2181; Doi: 10.1097/MLG.0b013e3181864acf 
10. Ikarashi T, Inamura K, Kimuray. Cystic Lymphangioma and Plunging Ranula Treated by OK-432 Therapy: A Report of Two Cases. Acta Otolaryngol (Stockh). 1994; 114(Suppl 511): 196-199; Doi: 10.3109/00016489409128331

11. Kinoshita M, Kida W, Nakahara H. Plunging ranula intruding into the parapharyngeal space treated with OK-432. Am J Otolaryngol. 2012; 33(3): 345-348; Doi: 10.1016/j.amjoto.2011.07.011

12. Fukase $\mathrm{S}$, Ohta $\mathrm{N}$, Inamura $\mathrm{K}$, Aoyagi M.Treatment of ranula with intracystic injection of the streptococcal preparation OK432. Ann Otol Rhinol Laryngol. 2003; 112(3): 214-220; Doi: 10.1177/000348940311200304

13. Rho MH, Kim DW, Kwon JS, Lee SW, Sung YS, Song YK, Kim MG, Kim SG. OK-432 Sclerotherapy of Plunging Ranula in 21 Patients: It Can Be a Substitute for Surgery. AJNR Am J Neuroradiol 2006; 27(5): 10901095

14. Kim KH, Sung MW, Roh JL, Han MH. Sclerotherapy for congenital lesions in the head and neck, Otolaryngol. Head Neck Surg. 2004; 131(3): 307-316; Doi: 10.1016/j.otohns.2004.02.018

15. Kim MG, Kim SG, Lee JH, Eun YG, Yeo SG. The Therapeutic Effect of OK432 (Picibanil)Sclerotherapy for Benign Neck Cysts. Laryngoscope. 2008; 118(12) :2177-2181; Doi: 10.1097/MLG.0b013e3181864acf

16. Ohta N, Fukase $S$, Watanabe T, Ito $T$, Aoyagi M. Effects and mechanism of OK-432 therapy in various neck cystic lesions. Acta Oto-Laryngologica. 2010; 130(11): 1287-1292; Doi: 10.3109/00016489.2010.483480
17. Ohta N, Fukase S, Suzuki Y, Ishida A, Aoyagi M.Treatments of Various Otolaryngological Cystic Diseases by OK-432: Its Indications and Limitations. Laryngoscope. 2010; 120(11): 2193-2196; Doi: 10.1002/ lary. 21141

18. Roh JL, Kim HS. Primary treatment of pediatric plunging ranula with nonsurgical sclerotherapy using OK-432 (Picibanil). Int J Pediatr Otorhinolaryngol. 2008; 72(9):1405-1410; Doi: 10.1016/j. ijporl.2008.06.003

19. Lee HM, Lim HW, Kang HJ, Chae SW, Hwang SJ, Jung KY et al.,. Treatment of ranula in pediatric patients with intralesional injection of OK-432. Laryngoscope. 2006; 116(6):966-969; Doi: 10.1097/01. Mlg.0000216809.90196.83

20. Kono M, Satomi T, Abukawa H, Haseqawa O, Watanabe M, Chikazu D. Evaluation of OK-432 Injection Therapy as Possible Primary Treatment of Intraoral Ranula. J Oral Maxillofac Surg. 2016; 75(2): 336-342; Doi: 10.1016/j.joms.2016.08.013

21. Roh JL. Primary Treatment of Ranula With Intracystic Injection of OK-432. Laryngoscope. 2006; 116(2):169-172; Doi: 10.1097/01. mlg.0000191458.23867.88

22. Ohta N, Fukase S, Suzuki Y, Kurakami K, Aoyagi M, Kakehata S. OK-432 treatment of ranula extending to the parapharyngeal space. Acta Oto-Laryngologica. 2014; 134(2):206-210; Doi: 10.3109/00016489.2013.847285 